\title{
Estados Unidos como caleidoscopio. Ensayo sobre las observaciones de viajeros y diplomáticos argentinos del fin de siglo
}

\author{
Paula BRUNO \\ CONICET - Universidad de Buenos Aires \\ pbruno@conicet.gov.ar
}

Recepción: 3 de enero de 2013 / Revisión: 16 de marzo de 2013

Aceptación: 8 de abril de 2013 / Publicación: diciembre de 2013

\begin{abstract}
RESUMEN
A partir de un análisis de cuatro figuras de la vida intelectual y diplomática argentina como Miguel Cané, Paul Groussac, Eduardo Wilde y Martín García Mérou hacia finales del siglo XIX y comienzos del XX, el artículo explora una serie de interpretaciones y miradas diversas sobre los peligros, desafíos y reacciones que provocó en la Argentina el ascenso progresivo de los Estados Unidos como un poder hegemónico continental. El propósito central del artículo es resaltar la existencia de voces, interpretaciones y múltiples registros discursivos sobre dicho fenómeno, argumentando que en la Argentina existió una suerte de caleidoscopio para observar a los Estados Unidos. Por lo tanto, se revisa críticamente el supuesto según el cual el antiimperialismo latinoamericano -y por ende argentino- estuvo dominado por una crítica culturalista e idealista del materialismo estadounidense. En particular, las figuras de Eduardo Wilde y en mayor medida García Mérou constituyen dos ejemplos de la conformación de nuevas interpretaciones optimistas acerca del ascenso de los Estados Unidos desarrolladas a partir de una experiencia diplomática concreta con dicho país y por lo tanto con una perspectiva desde adentro.
\end{abstract}

Palabras clave: intelectuales, Argentina, diplomacia cultural, Estados Unidos, Miguel Cané, Paul Groussac, Eduardo Wilde, Martín García Mérou, siglos XIX y XX.

\section{The United States as a Kaleidoscope. An Essay on the Observations of Turn-of-the-Century Argentine Travellers and Diplomats}

\begin{abstract}
From an analysis of four different Argentine intellectual and diplomatic figures of the late-nineteenth and early-twentieth century -Miguel Cané, Paul Groussac, Eduardo Wilde and Martín García Mérouthis article explores a series of different interpretations and worldviews of the dangers and challenges posed to Argentina by the gradual ascent of the United States as a continental hegemonic power, and the responses it aroused. The central purpose of the paper is to highlight the existence of diverse voices, interpretations and multiple discourses regarding this phenomenon, arguing that a sort of kaleidoscopic view of the United States emerged in Argentina. Hence, it seeks to review the assumption according to which Latin American anti-imperialism -and therefore its Argentine version- was dominated by a cultural and idealistic understanding of U.S. materialist culture. In particular, intellectual figures, such as Wilde and more importantly García Mérou, are two examples of the emergence of new optimistic interpretations about the ascendancy of the United States, developed in the context of concrete diplomatic experiences in that country and, thus, from inside perspectives.
\end{abstract}

Key words: Intellectuals, Argentina, Cultural Diplomacy, United States, Miguel Cané, Paul Groussac, Eduardo Wilde, Martín García Mérou, $19^{\text {th }}$ and $20^{\text {th }}$ Century. 
Sumario: 1. Introducción y contexto. 2. Estados Unidos: de la idealización al desencanto en los libros de viajes. 3. Estados Unidos: de la observación al conocimiento. 4. Palabras finales. 5. Referencias bibliográficas.

\section{INTRODUCCIÓN Y CONTEXTO}

Hacia fines del siglo XIX la identidad regional latinoamericana se reconfiguró y las relaciones con Estados Unidos se convirtieron en uno de los factores claves de esta redefinición. El país del Norte se perfiló decididamente como una potencia hacia fines del siglo XIX. Ese momento histórico coincidió con una nueva etapa de las relaciones internacionales, signada por la competencia por el control de los mercados internacionales. En el marco de este escenario, el expansionismo territorial estadounidense se desplegó mientras se estaban consolidando en el interior del país sentimientos nacionalistas, presentes en obras y folletos como Our country de Josiah Strong (1885), Manifest Destiny de John Fiske (1885) y The Influence of Sea Power on History de Alfred Mahan (1890), por mencionar algunos ejemplos. El nacionalismo enfervorizado y de corte imperialista se vio abonado por las ideas del "destino manifiesto", que otorgaba a los Estados Unidos la función de propagador de los valores morales, políticos y religiosos anglosajones ${ }^{1}$.

Por su parte, a partir de la década de 1880, las inversiones norteamericanas comenzaron a afluir en grandes cantidades hacia Latinoamérica. El hecho de que en las naciones de la región no existieran mercados financieros del todo consolidados, favoreció este flujo de capitales que generaba, para los Estados Unidos, altas ganancias. Como fenómeno complementario, como señaló Tulio Halperin Donghi: "Estados Unidos asumía el papel de gendarme al servicio de las relaciones financieras establecidas en la etapa de madurez del neocolonialismo"2. Como corolario de esta nueva posición asumida por Norteamérica, sus intervenciones en otros países del continente pasaron a ser moneda corriente en distintas coyunturas: frente a problemas limítrofes, cuando algún país latinoamericano no afrontaba sus deudas con el exterior (ya sea contraídas con una potencia europea o con los mismos Estados Unidos), o en momentos en los que el "gendarme" considerara que era necesario restablecer o sanear el orden político y la paz interior.

Estas medidas eran vistas con desconfianza e incredulidad por hombres políticos e intelectuales de algunos países latinoamericanos. Mientras tanto, Estados Unidos intentaba institucionalizar sus relaciones con América Latina, bajo los principios del "panamericanismo"3.

En este contexto, como es sabido, se produjo en 1898 la guerra entre España y Estados Unidos por el control de Cuba, Puerto Rico y Filipinas. En esa coyuntura, Estados Unidos mostró sin medias tintas su interés por tener el control de territorios considerados valiosos para consolidar su poderío económico. Históricamente, Cuba

1 Para panoramas generales sobre estos aspectos: Beyhaut - Beyhaut, 1990; Freeman Smith, 2000, pp. $73-105$.

2 Halperin Donghi, 1997, p. 292.

3 La bibliografía sobre este punto es abundante. Entre otros, véanse: BoESNER, 1990; SHEININ, 1998. 
se presentaba como un espacio codiciado, no sólo por su riqueza azucarera, sino también por su estratégica posición geográfica. La guerra dejó en evidencia las intenciones norteamericanas. La intervención en la lucha por la independencia cubana terminó convirtiendo a la nación del Norte en la nueva metrópoli de la isla ${ }^{4}$.

Si durante los años posteriores a las independencias hispanoamericanas intelectuales y políticos habían encontrado en Norteamérica un ejemplo y un modelo a seguir en aspectos vinculados con la organización de las nuevas unidades políticas, en el pasaje del siglo XIX al XX se expresaron voces que percibían a los Estados Unidos como una amenaza. Como parte de esta tendencia, algunos intelectuales pensaron y analizaron de manera sistemática los vínculos establecidos entre Latinoamérica y Estados Unidos. José Enrique Rodó se presentó como la voz paradigmática a la hora de señalar pares de opuestos que plantaban en términos antinómicos estas relaciones -como el de espíritu/materia-, sin por ello descartar absolutamente las ventajas del modelo norteamericano. Otros hombres de cultura, entre los que pueden destacarse Rubén Darío, por su parte, comenzaron a postular ideas ligadas a un movimiento que Oscar Terán denominó el primer antiimperialismo latinoamericano ${ }^{5}$. El motivo del Calibán condensó los aspectos del país del Norte que fueron criticados de manera sistemática por varios personajes. Así, la grandeza material norteamericana, los modales bruscos y superficiales de sus habitantes, las ideas políticas en vigencia y demás aspectos comenzaron a ser considerados como expresiones de un organismo bestial y avasallador 6 .

Junto con las intenciones de avance y predominio político y cultural, las ideas del Destino Manifiesto aparecían como un fantasma demasiado palpable y el expansionismo estadounidense provocó fuertes resistencias que cristalizaron en intervenciones de disconformidad, que bregaban por la unidad latinoamericana para contrarrestarlo defensivamente. Los intelectuales latinoamericanos que alzaron su voz dieron forma a un movimiento que tuvo proyecciones que excedían las fronteras nacionales. Como destaca Julio Ramos, gracias a la circulación de ideas propiciada por la migración y los desplazamientos de algunos intelectuales latinoamericanos -como Rubén Darío y José Martí-, las ideas de construcción de una identidad latinoamericana que contrarrestara a la omnipresencia norteamericana se fortaleció en el pasaje del siglo XIX al XX. Así, se configuró una noción de latinoamericanismo opuesta a la de panamericanismo, propiciada de manera unidireccional por los Estados Unidos ${ }^{7}$.

En este clima, ciertos discursos de intelectuales latinoamericanos comenzaron a redimir los valores hispánicos, que habían sido, generalmente, combatidos radicalmente luego de las independencias. De este modo, surgió una revalorización de Europa, sobre todo de corte cultural y espiritual, y la vertiente modernista apareció como una voz de defensa de los valores latinos frente a los anglosajones, generalmente relacionados con los principios del materialismo y la deshumanización. En un tono similar, la mayor parte de los relatos de viajeros del cambio de siglo observaban a Estados Unidos con desconfianza. Las críticas al materialismo desmesurado y traducido

4 CAGNI, 1999; PÉREZ, 1998.

5 Véase Terán, 1986.

6 Pueden consultarse: Fernández Retamar, 1993 y 2000; Morse, 1999.

7 Algunos textos sobre estos temas son: ArdaO, 1986; Ramos, 1989 y 2001. 
en aspectos sociales fueron recurrentes. Por su cantidad y densidad, estos discursos fueron ampliamente estudiados para dar cuenta de las miradas sobre Estados Unidos que se gestaron desde Latinoamérica ${ }^{8}$.

Pero no todas las voces intelectuales se expresaban en el mismo sentido. Pueden rastrearse intervenciones de figuras culturales que en el contexto del cambio de siglo se decidieron a explicar a los Estados Unidos haciendo de sus conocimientos exhaustivos del país uno de sus pilares argumentales. Además, entre la crítica y el ensalzamiento se dibujaron también miradas matizadas capaces de establecer juicios de valor menos categóricos. Para dar cuenta de este abanico de voces, en este artículo se recorren las representaciones de los Estados Unidos propuestas por cuatro figuras centrales de la cultura argentina del giro del siglo XIX al XX: Miguel Cané, Paul Groussac, Eduardo Wilde y Martín García Mérou.

\section{ESTADOS UNIDOS: DE LA IDEALIZACIÓN AL DESENCANTO EN LOS LIBROS DE VIAJES}

El libro Viajes, 1845-1847 de Domingo F. Sarmiento inauguró en la cultura argentina una tradición en la narración de travesías. Más allá de las diversas apreciaciones sobre este libro, es un hecho que su autor devino un interlocutor imaginario para quienes pretendían, hacia fines del siglo XIX, evaluar una parte sustancial del pasado cultural y político argentino, pero también para dar cuenta de las impresiones de sus propios derroteros por el mundo. Los relatos de Sarmiento devinieron una guía, una senda, y varios intelectuales siguieron sus huellas. Las lecturas sobre estos viajes sarmientinos y la variedad de temas y topografías que allí aparecen descritas, junto con la idea misma de movimiento y de cambio que la travesía impone en las percepciones de Sarmiento, parecen habilitar una diversidad de claves interpretativas. Algunos autores finiseculares optaron por detenerse en los tramos del viaje de Sarmiento por Europa para rescatar a un Sarmiento europeizado"; otros, en cambio, se detuvieron en las páginas sobre Estados Unidos, que muestran que el autor estaba entusiasmado ante un caudal de conocimientos e ideas políticas novedosas. De este modo, se inauguró con Sarmiento una matriz para empezar a pensar a Estados Unidos ${ }^{10}$.

Las ideas del autor de Facundo resultaron, en ocasiones, un parámetro con el que medirse. De hecho, fue Sarmiento quien, tempranamente, relacionó a Estados Unidos con la imagen de un organismo enorme y vigoroso; destacó:

No es aquel cuerpo social un ser deforme, monstruo de las especies conocidas, sino como un animal nuevo producido por la creación política, extraño como aquellos megaterios cuyos huesos se presentan aun sobre la superficie de la tierra ${ }^{11}$.

\footnotetext{
8 Para un estado del arte sobre estos temas puede consultarse Pita González - Marichal Salinas, 2012.

9 Bruno, 2008b; Pierini, 1998.

10 Botana, 1991, pp. 197-216.

11 SARMiento, 1993, p. 290.
} 
Sarmiento reivindicó los principios republicanos y federales que observó en la organización política norteamericana, evaluó positivamente su organización social, basada en la convivencia armónica de diferentes etnias, alabó las garantías civiles, las libertades políticas y la educación y ensalzó el progreso en todas sus manifestaciones, señalando que se trataba de un progreso particular, basado en la libertad, la democracia y la igualdad social. Desde su perspectiva, la realidad norteamericana encarnaba un modelo ideal que la Argentina debía emular.

Esta mirada optimista, que idealizó a Estados Unidos, cambió fuertemente de signo cuando se explayaron las plumas de figuras destacadas de las últimas décadas del siglo XIX. De hecho, Miguel Cané y Paul Groussac fueron dos viajeros finiseculares que expresaron de manera sistemática su rechazo a la hora de pensar Norteamérica como modelo.

La lectura que Miguel Cané realizó sobre los Estados Unidos se encuentra en su libro En viaje, publicado en $1884^{12}$. Las páginas referidas a este país se basan en sus impresiones de una travesía realizada en 1882. Su mirada, a tono con las opiniones de varios de sus contemporáneos se detiene en aspectos connotados negativamente ${ }^{13}$. Sus percepciones están signadas por la irritación que le generaron los efectos indeseados de la masificación en todas sus posibles manifestaciones. La supremacía de las relaciones mercantiles y la ausencia de valores espirituales se traducen, desde su perspectiva, en síntomas claros de vulgarización general de las costumbres. Estas coordenadas interpretativas convirtieron su travesía en una sucesión de sorpresas poco gratas que no hicieron más que confirmar sus prejuicios hacia al mundo yankee. Sostiene al respecto:

La impresión predominante es que uno se encuentra en un mundo nuevo, extraño, diferente a aquel en que estamos habituados a vivir. Juzgo que para un latino cuya vida ha pasado en el seno de sociedades cultas y educadas, será difícil naturalizarse con el modo de ser yankee, áspero y egoísta en sus formas ${ }^{14}$.

Cané apuntó que en cada uno de los rincones de ese mundo ajeno y considerado abominable reinaba el igualitarismo social manifestado en el borramiento de las barreras sociales que se evidenciaba en los rituales de la vida cotidiana de la sociedad estadounidense; como ejemplo, se refiere al transporte público de Nueva York, pun-

12 Miguel Cané nació en Montevideo, durante el exilio de sus padres, en 1851. Estudió en el Colegio Nacional de Buenos Aires y luego en la Facultad de Derecho, donde se graduó como abogado. Escribió en varios periódicos, entre ellos La Tribuna, El Nacional, La Prensa y La Nación. Fue diputado y senador nacional, embajador, profesor de la Universidad de Buenos Aires, director general de Correos y Telégrafos, intendente de Buenos Aires, ministro del Interior y de Relaciones Exteriores y Culto y decano de la Facultad de Filosofía y Letras. En 1898 redactó el Proyecto de Extradición de Extranjeros, posteriormente sancionado como Ley de Residencia. Ejerció cargos diplomáticos en numerosos países: Colombia, Venezuela, AustriaHungría, Alemania, España y Francia. Entre sus obras se cuentan: Ensayos (1877), En viaje (1884), Juvenilia (1884), Charlas literarias (1885), Notas e impresiones (1901), Prosa ligera (1903), Discursos y conferencias (1919, póstumo). Para detalles sobre la biografía de Cané: SÁEnz HAYes, 1955.

13 Para una lectura pionera del paso de Cané por los Estados Unidos pueden verse ColomBI, 2004; VIÑas, 1998, pp. 121-131.

14 CANÉ, 1884, p. 396. 
tualizando: "transporte democrático, símbolo perfecto de la igualdad, convenido"15. En la misma sintonía juzga el transporte, las relaciones amorosas, las calles y la moda, cada uno de estos objetos de observación es acompañado por el calificativo democrático/a. Esas pistas le permiten proponer una fórmula de síntesis para pensar en Estados Unidos como epítome de la "invasión democrática". Esta invasión es descrita con ojos alertas y cuidadosos. Para Cané, la democracia, entendida como igualdad social absoluta, signaba negativamente todas las formas de organización de la sociedad norteamericana. Es ilustrativa en este sentido su mirada sobre la prensa; refiriéndose a la misma, señala:

Si en alguna parte el aforismo de Girardin sobre la impotencia de la prensa tiene aplicación, es en Norte América. Los diarios se tiran á centenares de millares y constituyen uno de los géneros de empresa industrial que reporta más beneficio. Pero es el anuncio y la información lo que les da vida y no la opinión política. ¿Qué le importa a un yankee lo que piensa un diario? Lo compra, va a los telegramas y luego á los avisos. La verdad es que en el día de la prensa universal tiende á tomar este carácter. El valor e importancia del Times consiste en su preocupación incesante de reflejar la opinión, con todas sus aberraciones, en vez de pretender dirigirla ${ }^{16}$.

Los motivos por los cuales esta prensa es impotente no son tan obvios para el lector como Cané sugiere ${ }^{17}$. La observación crítica puede desglosarse en varios ejes. En primer lugar, el hecho de que la prensa se haya convertido en una más de las industrias de los Estados Unidos se halla en consonancia con la idea de que todas las esferas de la vida humana son mercantilizables y, por tanto, desde la perspectiva de este observador, condenables. Además, esta mercantilzación habría traído consigo la renuncia a una función fundamental de la prensa: la de guiar a la opinión. Esto se traduce, desde la perspectiva de Cané en una oportunidad perdida, y la democratización de la palabra que hace que la opinión se refleje en todos sus matices y con todas sus "aberraciones" convierte a la prensa en un espacio contaminado y socialmente abierto. En suma, ante los ojos del observador, un potencial instrumento, útil como pocos para formar a la opinión pública, se había convertido en Norteamérica en una simple industria que producía en serie noticias y avisos.

Esta imagen de la prensa yankee lejos está de presentar a un diario como la herramienta dilecta de un grupo social ilustrado para ejercer una pedagogía cívica. Esa función es la que Cané propone recuperar hacia fines del siglo XIX, ya pensando en lo que debería ponerse en práctica en Buenos Aires. La prensa es un instrumento eficaz para emitir discursos que moldeen la opinión y un arma para quien pretenda tener algún tipo de resonancia en el ámbito público. Es, además, un elemento clave para adoctrinar. Esta simpatía por la vigencia de una aristocracia social e intelectual se reforzó y se convirtió en un baluarte a ser defendido para pensar la Argentina luego de los desencantos ante Estados Unidos.

\footnotetext{
15 Ibídem, p. 394.

16 Ibídem, p. 397.

17 Sobre esta cuestión me permito remitir a BRUNO, 2008a.
} 
De hecho, en las últimas décadas se publicaron estudios que analizaron algunos aspectos vinculados con el ideario de Miguel Cané de estos años. Éste es el caso de las lecturas propuestas por Oscar Terán y por Jeffrey Needell, coincidentes en varias de sus apreciaciones ${ }^{18}$. En ambos análisis se exploraron las reacciones de Cané frente a la gran diversidad de procesos sociales, políticos, económicos y culturales aglutinados bajo el rótulo de "modernización". Las expresiones "lamento" y "melancolía" presentes en los títulos de los aportes de estos autores dan pautas claras acerca de la lectura de carácter pesimista postulada por Cané ante la modernización, interpretación que encarna la voz de una "aristocracia" argentina que se veía aturdida por los múltiples efectos, algunos anhelados y otros temidos, de los procesos de transformación que sucedían de manera rauda e incomprensible.

El registro propuesto por Cané se mantuvo y recreó en las obras de otros intelectuales que visitaron los Estados Unidos en la década de 1890 y se potenció en el contexto de la guerra de 1898. Como ilustración de las continuidades radicalizadas en las opiniones sobre Estados Unidos pueden presentarse los comentarios altamente peyorativos ofrecidos por Paul Groussac en su libro Del Plata al Niágara, publicado apenas un año antes de los acontecimientos de $1898^{19}$. Esta obra recoge relatos de los viajes que concretó en 1893 por Chile, Perú, México, algunos puntos de América Central y Estados Unidos. En diferentes capítulos destinados a estas geografías se encuentran opiniones sobre las configuraciones sociales de los países latinoamericanos y sus efectos, el ascenso del socialismo y el anarquismo y la presencia de estas corrientes políticas en la vida cotidiana europea, la grandeza material yankee y sus limitaciones, la decadencia de los centros urbanos europeos, las derivaciones de la igualdad social en Estados Unidos, la función de la prensa en las sociedades modernas y un variado abanico de tópicos característicos del fin de siglo ${ }^{20}$.

En lo que respecta específicamente a Estados Unidos, este intelectual de origen francés radicado en Argentina, destacaba:

Me temo á veces que la modernísima democracia consista en levantar cada pueblo sus moradas á la moda del día, arrasando las de sus predecesores, para que cada generación humana no deje más rastros en la tierra que los del ganado transhumante. Esa democracia niveladora, amante de las tablas rasas y gran fabricante de self-made men, la contemplaremos luego en su forma aguda, en esa ocupación anhelante y febril del Extremo Oeste que remeda, en medio de todas sus innovaciones prácticas, una

\footnotetext{
18 NeEdell, 1999, pp. 551-588; Terán, 2000, pp. 13-82.

19 Paul Groussac nació en Toulouse, Francia, en 1848. Arribó a la Argentina en 1866 y en 1871 ya era reconocido en los más prestigiosos cenáculos intelectuales de la época. Ocupó el cargo de Director de la Biblioteca Nacional en el período comprendido entre 1885 y 1929; editó y dirigió La Biblioteca entre 1896 y 1898 y Anales de la Biblioteca entre 1900 y 1915; publicó artículos de diversas temáticas en Revista Argentina, Revista de Filosofia, La Unión, La Razón, La Nación, El País y El Diario, entre otros. Sus obras históricas más destacadas son Santiago de Liniers, conde de Buenos Aires (1907) y Mendoza y Garay, las dos fundaciones de Buenos Aires (1916). Otros estudios históricos del autor son Ensayo histórico sobre el Tucumán (1882), Ensayo crítico sobre Cristóbal Colón. Historia y leyenda (1892), Historia de la Biblioteca Nacional (1893), El Congreso de Tucumán (1916), Estudios de historia argentina (Recopilación de estudios anteriores, 1918). Sobre Paul Groussac pueden consultarse: BRUNO, 2005a y 2005b.

20 Para análisis sobre estas temáticas: BRUNo 2005b; VIÑAS, 1998, pp. 103-112.
} 
regresión moral á los éxodos antiguos, al nomadismo asiático: la tienda del pastor alumbrada con luz eléctrica ${ }^{21}$.

Esta observación, escrita en México, no hizo más que confirmarse cuando el viajero llegó a los Estados Unidos. El recorrido por varias ciudades y parajes del país del Norte se eslabonó, como puede verse en los títulos de las cartas de viaje publicadas en su libro, a través de California, Salt Lake City, Chicago, Washington, Massachusetts, Nueva York. A tono con otros personajes de la época, su mirada de los Estados Unidos lejos estaba de proyectar modelos a seguir o parámetros civilizatorios, sino más bien todo lo contrario.

La primera sensación al pisar suelo estadounidense, tranquilizadora en relación con las excursiones al Perú y a México, se esfumaría rápidamente hasta convertirse en repulsión y fastidio generalizado hacia todo lo que se erigía en los "dominios del Tío Sam", sentimientos que incluso hacían añorar el ritmo de vida y las configuraciones sociales de las aldeas casi coloniales anteriormente visitadas. Pocos detalles del país del norte eran reivindicados, y los juicios sobre la dinámica política, los comentarios acerca de costumbres y modos de vida y las opiniones sobre distintas prácticas culturales conformaron un conglomerado de observaciones signado por la fobia, la reacción violenta y la ironía ${ }^{22}$. En síntesis, Groussac describió a la sociedad estadounidense como una gran multitud con la apariencia de un animal tosco, que no podía ser conducida por una aristocracia intelectual dado que no existía allí siquiera una minoría ilustrada. La democracia se transformaba, entonces, en la tiranía de las mayorías, y el camino apresurado hacia la extensión desmedida de los ideales igualitaristas implicaba una insoportable mediocridad, de ningún modo reivindicable ni paradigmático ante los ojos del viajero de origen francés.

La carga crítica de estas claves interpretativas se agudizó en el contexto del conflicto de 1898 entre España y Estados Unidos por el control de Cuba, Puerto Rico y Filipinas, resuelto finalmente a favor de la potencia americana. En esta coyuntura, Groussac señaló que el expansionismo estadounidense y sus intenciones de consolidar un enorme poderío de ocupación militar estaban apuntalados por la pretensión de difundir ideales típicos de un pueblo dotado de incisivos colmillos ${ }^{23}$. Su tono alarmado apuntaba a alertar contra la posibilidad de que se repitiera en alguna otra región de la América hispana la misma situación que en México, víctima de una "brutal invasión que en pocos años puso la mitad de su territorio en poder de Estados Unidos", injusticia validada exclusivamente desde la "sacrosanta doctrina de Monroe"24.

Aunque este fue el tono predominante de las opiniones sobre Estados Unidos, no todas las voces intelectuales se alzaban en el mismo sentido. Como se verá en la próxima sección, pueden rastrearse intervenciones de ciertas figuras culturales que en el contexto del cambio de siglo se expresaron con distintos acentos a la hora de evaluar las realidades norteamericanas.

\footnotetext{
21 Groussac, 1897, p. 181.

22 VIÑAS, 1998, pp. 103-112.

23 Para un desarrollo más extenso de estos argumentos: BRUNO, 2012, pp. 43-66.

24 Groussac, 1897, p. 219.
} 


\section{ESTADOS UNIDOS: DE LA OBSERVACIÓN AL CONOCIMIENTO}

Las voces de intelectuales que no se inscriben en una línea crítica, pesimista o antiimperialista no conforman un frente de opinión homogéneo y han sido menos estudiadas. Se revisan aquí dos expresiones de esta tendencia. La primera de ellas proviene de las observaciones realizadas por Eduardo Wilde ${ }^{25}$.

Wilde recorrió en 1890 Europa, Asia y Estados Unidos. Este viaje fue seguido por otros cercanos en el tiempo: el segundo concretado entre 1892 y 1893 y el tercero emprendido entre 1896 y 1898. Luego de pasar dos años en la Argentina, a fines de 1899 Wilde recibió el nombramiento como Embajador de Estados Unidos y México, en remplazo de Martín García Mérou -figura tratada también en este ensayo-. Se instaló primero en Washington, por casi un año, luego pasó a la flamante Legación de Bélgica y Holanda y, por último, estuvo a cargo de la embajada en España.

Sus escritos de experiencias de viajes y diplomáticas fueron publicados casi en su totalidad. Sus cartas fueron publicadas en los libros Viajes y observaciones y Por mares y por tierra. Wilde no se vio condicionado por la agenda que habían marcado los padres fundadores (como el ya mencionado Sarmiento) al plantear la tensión entre Europa y Estados Unidos como espacios ejemplares o modelos evitables. Legó miradas sobre diferentes geografías sin pretender moralizar desde ellas. Por ejemplo, aunque expuso su fastidio frente a la presencia obrera y ante la pobreza creciente que generaba que en España no se pudiera caminar sin toparse con un mendigo a cada paso, estas miradas peyorativas sobre el "pueblo", a diferencia de las postuladas por Cané, no se tradujeron en una idealización de la existencia de grupos que atesoraran valores tradicionales y que por ello pudieran hacer frente a la multitud avasalladora con actitud aristocratizante.

A su vez, en Estados Unidos, la democracia igualadora en su sentido social no fue tampoco por él percibida en términos de peligro. Aunque en varios de sus escritos tempranos planteó ciertas reservas ante el avance de la igualación, cuando viajó por los Estados Unidos se detuvo más bien a observar la unión de la ciencia y el comercio, del arte y la mercancía, que convivían extraña pero armónicamente. No obtuvo de allí lecturas despectivas sobre la masificación vulgarizadora. De alguna manera, Wilde hizo cierta apología de estas nuevas coordenadas que estaban acompasando la realidad norteamericana. Ya desde su juventud había sido un hombre práctico y no

25 Eduardo Wilde nació en Tupiza (Bolivia) -lugar en el que sus padres estaban exiliados- en 1844, murió en Bruselas en 1913. Realizó sus estudios secundarios en el Colegio del Uruguay, se graduó como doctor en Medicina en la Universidad de Buenos Aires en 1870. Ocupó numerosos cargos políticos: fue diputado de la Legislatura de Buenos Aires en 1879, ministro de Justicia e Instrucción Pública desde 1882 hasta 1886 -bajo su ministerio se realizó el Congreso Pedagógico y se sancionó la Ley de Educación Común, 1420-, fue ministro del Interior desde 1886 hasta 1889, bajo la presidencia de Juárez Celman. Durante la segunda presidencia de Julio A. Roca fue nombrado ministro plenipotenciario - cargo que desempeñó en España y en Bélgica hasta su fallecimiento-. Escribió en destacados periódicos de su época y se desempeñó además como profesor, catedrático y publicista, fue autor distinguido de obras médicas y fundador del Instituto Pasteur, además impulsó las obras de Puerto Madero y creó el Departamento Nacional de Higiene. Entre sus obras editadas se destacan: Tiempo perdido (1878), Prometeo y Cía. (1899), Viajes y observaciones (1892, 2 volúmenes), Por mares y por tierras (1899, 2 volúmenes) y Aguas abajo (1914, de publicación póstuma). Una biografía de Eduardo Wilde puede consultarse en BRUNO, 2011. 
dudaba en repetir: "creo que el progreso del mundo y la felicidad de sus habitantes depende de la industria, del comercio y de la ciencia, como perfeccionadora de esas dos cosas"26. Y si hacia 1890 , ya con mayor experiencia y conocimiento del mundo, manifestó cierto vértigo frente a un progreso material que se traducía en algunas carencias (por ejemplo, en no tener tiempo para reflexionar en los trenes, "más veloces que las pesadas meditaciones" y movidos por una "rapidez que abruma, desconcierta y marea" ${ }^{27}$ ), ver la producción fabril, los sistemas de transporte y las tramas urbanas de distintas ciudades norteamericanas lo convirtieron en un ferviente admirador del progreso material, más allá de sus costos sociales y de sus potenciales efectos vulgarizadores.

Como se mencionó, Eduardo Wilde remplazó a Martín García Mérou por un breve lapso en la legación de Estados Unidos ${ }^{28}$. De hecho, ocupó el cargo entre dos períodos en el que el mismo fue ocupado por García Mérou; éste tuvo una destacada participación en la constelación cultural y diplomática de su época, sobre todo por su actuación en naciones latinoamericanas (Venezuela, Colombia y Brasil), en los Estados Unidos y, más fragmentariamente, en capitales europeas (Madrid, Berlín). De las figuras aquí estudiadas fue la que permaneció afincada en Norteamérica por más tiempo. Estuvo radicado por ocho años en Washington (durante dos períodos: 1896 -1900 y 1901-1905) y conoció una cantidad considerable de ciudades norteamericanas. Tanto en Estados Unidos como en otras naciones que desempeñó funciones diplomáticas, se dedicó a escribir libros que reúnen observaciones sobre la cultura y la historia de otros países, esto le otorga un plus diferencial, dado que sus obras que versan sobre otros territorios, lejos de ser los clásicos relatos de viaje de la época, son estudios ordenados y muy bien informados; este es el caso, por ejemplo, de los capítulos dedicados a Colombia de Confidencias literarias (1893) y a la cultura literaria brasileña en El Brasil intelectual (1900). En el mismo sentido se inscriben tres obras sobre los Estados Unidos: Estudios americanos (1900 -el libro está dedicado a Estados Unidos, a excepción de un ensayo-), Historia de la Diplomacia Americana (dos volúmenes publicados en 1904 sobre la política internacional de los Estados Unidos durante el siglo XIX y comienzos del XX- y Apuntes económicos e industriales sobre los Estados Unidos (1905).

Conocedor de los libros de viajes de extranjeros a Argentina, García Mérou mostró cierta disconformidad por los acentos de los relatos de viajeros. En este sentido, en

26 WILDE, 1923, p. 90.

27 WiLdE, 1892. II, p. 154.

28 Martín García Mérou nació en Buenos Aires en 1862, cursó sus estudios en el Colegio Nacional y en la Facultad de Derecho de la Universidad de Buenos Aires. A los 19 años tuvo su bautismo en la diplomacia, fue secretario privado de Miguel Cané en su misión diplomática por Colombia y Venezuela. Fue, más tarde trasladado a París y Julio A. Roca lo designó, en 1886, ministro residente en Paraguay. En 1891 fue nombrado ministro plenipotenciario de distintas legaciones argentinas, y con ese cargo residió en Perú (1891 - 1894), Brasil (1894 - 1896) y los Estados Unidos (1896 - 1900 y 1901 - 1905). Fue representante argentino en la Segunda Conferencia Panamericana realizada en México y ocupó, hacia 1905 y por escasos meses, el cargo de ministro plenipotenciario en la legación de Alemania, Austria, Hungría y Rusia. Al mismo tiempo que su carrera diplomática transcurría, la trayectoria intelectual de García Mérou se fue enriqueciendo, dado que comenzó a incursionar en la escritura de diversos géneros: novela, ensayos, impresiones de viaje, historia y distinto tipo de memorias. 
un texto titulado "Viajeros en Sudamérica", ofreció prácticamente un tratado sobre los libros de viajeros y no duda en subrayar que varios de estos relatos desconocen el terreno del que opinan, tienen prejuicios sobre lo observado, son pintoresquistas más que realistas ${ }^{29}$. Sus obras se distancian, sistemáticamente, de las lecturas de viajero, tanto por sus formatos como por su tono. Lejos de ser textos de impresiones u observaciones, son escritos basados en un conocimiento exhaustivo de las realidades observadas en Estados Unidos. La combinación de sus opiniones sobre el género y la oportunidad única de vivir en Norteamérica e involucrarse en sus dinámicas se tradujo en sus estudios. Sus miradas sobre Estados Unidos pueden resumirse en unas cuantas consideraciones. Una de ellas surgida durante una estadía en Chicago; allí destacó:

La vida americana está hecha de contrastes. En las mismas grandes ciudades de este país, al lado de los edificios majestuosos de veinte pisos de altura, hay barrios enteros de casas de madera, con aceras del mismo material, en que habitan millares de seres humanos en un hacinamiento y promiscuidad que nada tiene que envidiar a las viejas capitales del antiguo continente ${ }^{30}$.

Sus observaciones no tendían a idealizar los parámetros civilizatorios europeos, se mostraban abiertas a reconsiderar a Estados Unidos como un modelo en un marco diferente al conocido por Sarmiento. Y, justamente, era ese nuevo contexto de expansión económica y territorial y modernización material lo que entusiasmó a García Mérou. En varios de sus escritos sostuvo que la armonía de la sociedad norteamericana era una de las claves para entender las realidades del país; resume esta premisa con la siguiente pregunta:

¿Qué talismán secreto posee la vida de estas democracias que así transforma y funde en su crisol lo más variado de caracteres de la raza humana y los eleva a la dignidad de ciudadanos, conscientes de su valer y respetuosos del deber y del derecho? ${ }^{31}$.

Entre los valores de la sociedad norteamericana, destacó la "generosidad de estos hombres que algunas veces han empezado la vida desde los escalones más bajos de la escala social" y se sirvió de la imagen del pionner para dar cuenta de las virtudes cívicas de los ciudadanos norteamericanos.

Por su parte, la grandeza material norteamericana no espantaba a García Mérou como a varios de sus contemporáneos. En sus escritos se encuentran metáforas ligadas a las del gigantismo norteamericano, presentes ya en las observaciones de Sarmiento - con connotación positiva-y Paul Groussac - con signos negativos-, pero en su caso ese gigantismo no está asociado a lo monstruoso y lo temible:

\footnotetext{
29 García Mérou, 1900, p. 48.

30 Ibídem, p. 15.

31 Ibídem, p. 18.
} 
Este país extraordinario en que todo es grande, en que todo parece transportado a escala de aquellos habitantes Saturno pintados por Voltaire en la historia de la peregrinación de Micrómegas ${ }^{32}$.

Estas observaciones generales sobre Estados Unidos se completan en la obra de García Mérou con una gran cantidad de datos y estadísticas sobre esferas de lo más diversas. Así, por ejemplo, en el libro Apuntes económicos e industriales sobre los Estados Unidos, documenta y describe fenómenos como el desarrollo industrial, los factores de producción -potencialidades y límites-, la estructura agraria, los mercados y los transportes, pero también analiza aspectos sociales, como los vinculados a la educación en distintos niveles y el mundo del trabajo ${ }^{33}$.

En un sentido complementario, García Mérou asumió el desafío de pensar el expansionismo contemporáneo connotándolo de manera positiva en el marco de un clima de opinión que, como se ha visto, avanzaba en sentido contrario. En su Historia de la diplomacia americana, señala que su libro debe servir como guía a las nuevas generaciones que, desprendiéndose de los prejuicios sobre Estados Unidos, deben avanzar en un conocimiento acabado de sus cualidades. Allí define al imperialismo en los siguientes términos:

Me he visto conducido a investigar las tendencias de la política internacional americana y los procedimientos de su diplomacia. La última faz de dicha política, o lo que se llama imperialismo, no es sino la culminación lógica de una irresistible necesidad de expansión territorial que se manifiesta desde los albores de la vida independiente de la más grande de las democracias modernas ${ }^{34}$.

En suma, la mirada de García Mérou, sostenida por observaciones menos coyunturales que las de la mayoría de sus contemporáneos, se sostuvo en dos pilares poco transitados por los mismos: el primero, se encuentra en sus conocimientos exhaustivos del país; el segundo, en sus premisas casi contra-intuitivas en un contexto en que las críticas categóricas ante el imperialismo norteamericano eran las dominantes.

\section{PALABRAS FINALES}

En el contexto de las independencias hispanoamericanas, los Estados Unidos no contaban con políticas que pusieran su atención de manera sistemática en América Latina. La Doctrina Monroe (1823) había tenido en sus inicios un contenido defensivo y preventivo frente a las potencias europeas y sus intenciones de intervenir o colonizar territorios del continente americano, pero no traducía, en primera instancia, una intención de control de Norteamérica sobre el resto del continente. En este clima, miradas como las de Sarmiento, de clara impronta tocquevilliana, propusieron a Estados

\footnotetext{
32 Ibídem, p. 60.

33 García Mérou, 1905 , p. 1.

34 García MÉrou, 1904, p. 1.
} 
Unidos como la nación portadora de los adelantos y las novedades políticas, sociales y económicas a emular ${ }^{35}$.

La situación del pasaje del siglo XIX al XX era claramente diferente. Una vez que los Estados Unidos lograron establecer la paz interior en su territorio, su atención pasó a estar fijada en el resto del continente y se comenzaron a desplegar las bases para ejercer el control sobre el mismo. Así, fue en torno a 1870, cuando situaciones como el fin de la guerra civil, el crecimiento económico notable del país y la modernización de las estructuras productivas, que el gran país del Norte posó sus ojos en América Central, del Sur y el Caribe.

Hacia fines del siglo XIX, Estados Unidos alcanzó un nivel de producción más alto que las potencias europeas como Gran Bretaña, Francia y Alemania. En este marco, la industrialización y la conformación de grandes consorcios se convirtieron en realidades que comenzaron a acompasar los ritmos de la economía norteamericana e internacional. De este modo, se delineó una configuración internacional caracterizada por los trusts y los monopolios y las nuevas dinámicas económicas dieron paso a otras formas de articulación de las relaciones entre la nación del Norte y los países latinoamericanos. Ahora, América Latina se presentaba, a la vez, como un potencial y gigantesco mercado consumidor de manufacturas industriales norteamericanas y como la región ideal para la obtención de ciertos recursos necesarios para saciar demandas de productos primarios y alimentos. La atención hacia la región, por lo tanto, comenzó a profundizarse, no sólo por la proximidad territorial, sino también porque las riquezas naturales de la región se convirtieron en un polo de atracción.

Tuvieron lugar, entonces, varias iniciativas norteamericanas de distinto calibre. Mientras que, por un lado, comenzaron a implementarse políticas traducidas en la intervención, directa o indirecta, en los territorios latinoamericanos, por otro, se intentó consolidar el proyecto de la unión panamericana, entendida como una alianza entre los países americanos bajo control norteamericano.

Estas transformaciones se vieron reflejadas en las obras de intelectuales que se acercaron a Estados Unidos con la intención de tratar de comprender las dinámicas que explicaran su grandeza y su ímpetu. Se delinearon así distintas tendencias interpretativas. Mientras que en la década de 1840 el tono optimista de Sarmiento era el dominante, en las figuras del cambio de siglo analizadas aparecieron otras voces. La lectura más pesimista de Cané, radicalizada en las impresiones de Groussac, se inscribió sin fisuras en las críticas al materialismo norteamericano entendido como un rasgo de desmesura y barbarie disfrazada de progreso. Las observaciones de Eduardo Wilde, en cambio, presentan otros matices; reivindicó el progreso material y lo entendió como la sana expresión de una nación dinámica. Las obras de Martín García Mérou, en cambio, apostaron a un registro optimista para pensar Estados Unidos. Pero éste no era ya el de las idealizaciones de la primera mitad del siglo XIX, sino un nuevo optimismo surgido del conocimiento y la experiencia obtenida al involucrarse en las dinámicas diferentes a las de los viajeros. Este plus diferencial convierte a García Mérou no solamente en un espectador de usos y costumbres sociales, culturales y políticas sino también en alguien que trata de escribir "desde adentro". Los acentos

\footnotetext{
35 RoLdÁN, 2005.
} 
de sus comentarios así lo confirman. Acompaña esta intención una mirada ya no de las promesas presentes en aquellos Estados Unidos que observó Sarmiento, sino en una decisión que apuntaba a mostrar que las verdaderas virtudes del país del Norte debían ser rastreadas en el mismo imperialismo que varios de sus contemporáneos, como se ha subrayado, juzgaban y condenaban. Este recorrido comparativo por las voces de Cané, Groussac, Wilde y García Mérou pretende, por un lado, agudizar la evaluación de voces que encarnaron distintos trajes: viajeros casuales, diplomáticos en actividad, mediadores culturales entre geografías, observadores alarmados y estudiosos $^{36} ; \mathrm{y}$, por otro, aportar referencias y líneas interpretativas para completar el panorama de miradas finiseculares sobre los Estados Unidos y otorgar cierto relieve a las voces que pretendieron posicionarse en la vereda opuesta a la del antiimperialismo latinoamericano, ya no idealizando un modelo, sino evaluando una realidad que les fue contemporánea. Estados Unidos, en suma, parecía no ser un motivo estático ante las miradas de los contemporáneos, más bien se ofrecía como un caleidoscopio dador de distintas posibilidades de observación.

\section{REFERENCIAS BIBLIOGRÁFICAS}

ARDAO, Arturo

1986 "Panamericanismo y latinoamericanismo". En ZeA (coord.), América Latina en sus ideas. México. Siglo XXI, pp. 157-171.

AuZA, Néstor

1975 "Martín García Mérou: un estudioso de la sociedad americana de fines del siglo XIX y comienzos del XX". Investigaciones y ensayos. Buenos Aires. $\mathrm{n}^{\circ} 18$, enero-junio, pp. 311-333.

Beyhaut, Gustavo - Beyhaut, Hélène

1990 América Latina, vol. 3: De la independencia a la Segunda Guerra Mundial. México. Siglo XXI.

BOESNER, Demetrio

1990 Relaciones internacionales de América Latina. Breve historia. Caracas. Editorial Nueva Sociedad.

Botana, Natalio

1991 "Sarmiento y el orden político: libertad, poder y virtud". En Botana, La libertad política y su historia. Buenos Aires. Sudamericana, pp. 197-216.

BRUNO, Paula

2005a Paul Groussac. Un estratega intelectual. Buenos Aires. Fondo de Cultura Económica - Universidad de San Andrés

2005b Travesías intelectuales de Paul Groussac. BRUNO, estudio preliminar y selección de textos. Colección "La ideología argentina". Buenos Aires. Universidad Nacional de Quilmes.

2008a "Lecturas de Miguel Cané sobre la función de la prensa en las sociedades modernas". Cuadernos Americanos. México. Nueva Época, vol. 5, nº 123, enero-marzo, pp. 113-138.

36 Sobre este punto, ver también el artículo de Scarfi en este mismo dossier. 
2008b "Miguel Cané y Paul Groussac tras las huellas de los Viajes de Sarmiento". En FerNÁNDEZ - Geli - Pierini (Comps), Derroteros del viaje en la cultura: mito, historia y discurso. Rosario. Prohistoria Ediciones.

2011 Pioneros culturales. Biografias de una época, 1860-1910. Buenos Aires. Siglo XXI Editores.

2012 "Mamuts vs. hidalgos. Lecturas de Paul Groussac sobre Estados Unidos y España en el fin-de-siglo". En Pita González - Marichal Salinas (Comps), Pensar el antiimperialismo. Ensayos de historia intelectual latinoamericana 1900-1930. El Colegio de México - Universidad de Colima. México, pp. 43-68.

Cagni, Horacio

1999 La guerra hispanoamericana y el inicio de la globalización. Buenos Aires. Olcese.

CANÉ, Miguel

1884 En viaje, 1881-1882. Paris. Garnier Hermanos.

1918 Notas e impresiones. [1901]. Buenos Aires. La cultura argentina.

Colombi, Beatriz

2004 Viaje intelectual. Migraciones y desplazamientos en América. Latina 1880-1915. Rosario. Beatriz Viterbo Editora.

FERnÁnDEZ Retamar, Roberto

1993 Algunos usos de civilización y barbarie. Buenos Aires. Editorial Letra Buena.

2000 Todo Calibán. La Habana. Editorial Letras Cubanas.

FREEMAN SMITH, Robert

2000 "América Latina, los Estados Unidos y las potencias europeas". En Bethell (Coord.), Historia de América Latina. vol. 7. Barcelona. Crítica. pp. 73-105.

García Mérou, Martín

1900 Estudios americanos. Buenos Aires. Félix Lajouane.

1904 Historia de la diplomacia americana: política internacional de los Estados Unidos. Buenos Aires. Félix Lajouane. 2 tomos.

1905 Apuntes económicos e industriales sobre los Estados Unidos. Buenos Aires. Félix Lajouane.

Groussac, Paul

1897 Del Plata al Niágara. Buenos Aires. Administración de La Biblioteca.

1898 España y Estados Unidos. Función dada en el Teatro de la Victoria el 2 de mayo de 1898. Conferencias de los Señores Dr. Roque Sáenz Peña, Paul Groussac y Dr. José Tarnassi. Bajo el patrocinio del Club Español de Buenos Aires, a beneficio de la Suscripción Nacional Española. Prólogo del Dr. Severiano Llorente. Buenos Aires. Compañía General de Billetes de Banco.

Halperin Donghi, Tulio

1997 Historia contemporánea de América Latina. Madrid. Alianza Editorial.

McGann, Thomas

1960 Argentina, Estados Unidos y el sistema interamericano, 1880-1914. Buenos Aires. Eudeba.

Morse, Richard

1999 El espejo de Próspero. Un estudio de la dialéctica del Nuevo Mundo. México. Siglo XXI.

NeEDELL, Jeffrey

1999 "Optimism and Melancholy: Elite response to the fin de siècle bonaerense". Journal of Latin American Studies. Cambridge, vol. 31, part 3, october, pp. 551-588. 
PÉREZ, Louis

1998 The War of 1898: The United States and Cuba in History and Historiography. Chapel Hill. University of North Carolina Press.

PIERINI, Margarita

1998 "Sarmiento en París. Viaje al corazón de la modernidad". Actual. Mérida, vol. 1, n 38, enero-abril, pp. 177-196.

Pita GonzÁlez, Alexandra - Marichal Salinas, Carlos

2012 "Introducción. Pensar el antimperialismo". En Pita González - Marichal Salinas (Comps), Pensar el antimperialismo. Ensayos de historia intelectual latinoamericana, 1900-1930. México DF. El Colegio de México - Universidad de Colima. pp. 9-40.

Ramos, Julio

1989 Desencuentros de la modernidad en América Latina. Literatura y politica en el siglo $X I X$. México. Fondo de Cultura Económica.

2001 "Hemispheric Domains: 1898 and the Origins of Latin Americanism". Journal of Latin American Cultural Studies. Oxford, vol. 10, nº 3, pp. 237-251.

Roldán, Darío

2005 “Sarmiento, Tocqueville, los viajes y la democracia en América". Revista de Occidente. Madrid, $\mathrm{n}^{\mathrm{o}} 289$, pp. 35-60.

SARMiento, Domingo Faustino

1993 Viajes por Europa, África y América, 1845-1847. [1849 y 1851, 2 volúmenes]. Buenos Aires. Fondo de Cultura Económica.

SÁEnZ HaYes, Ricardo

1955 Miguel Cané y su tiempo (1851-1905). Buenos Aires. Kraft.

SHEININ, David

1998 Searching for Authority: Pan Americanism, Diplomacy and Politics in United StatesArgentine Relations. 1910-1930. New Orleans. University Press of the South.

TERÁn, Oscar

1986 “El primer antiimperialismo latinoamericano". En TERÁN, En busca de la ideología argentina. Buenos Aires. Catálogos.

2000 "El lamento de Cané". En Terán, Vida intelectual en el Buenos Aires fin-de-siglo (1880-1910). Derivas de la “cultura cientifica”. Buenos Aires. Fondo de Cultura Económica, pp. 13-82.

VIÑAS, David

1998 "Sarmiento en seis incidentes provocativos"; "Groussac: las ironías y los privilegios"; "Eduardo Wilde: ecologismo y misantropía"; "Cané o los contratiempos de un gentleman”. En Viñas, De Sarmiento a Dios. Viajeros argentinos a USA. Buenos Aires. Sudamericana. pp. 11-29; 103-112; 113-120; 121-131.

WiLDE, Eduardo

1892 Viajes y observaciones. Cartas a La Prensa. Buenos Aires. Imprenta Biedma. Tomos I-II.

1899 Por mares y por tierra. Buenos Aires. Peuser.

1923 Tiempo Perdido [1878]. Buenos Aires. Peuser 